\title{
O CURSO TÉCNICO EM ESTRADAS NA ESCOLA TÉCNICA FEDERAL DE MATO GROSSO: MOVIMENTOS INICIAIS
}

\author{
Pedro José de Barros ${ }^{1}$ \\ Miriam Fábia Alves²
}

\section{Resumo}

Este artigo apresenta um recorte da dissertação "O Curso Técnico em Estradas: das origens à implementação na Escola Técnica Federal de Mato Grosso", de cunho histórico-documental e bibliográfico, defendida na Linha de Pesquisa "Estado, Políticas e História da Educação", do Programa de Pós-Graduação em Educação da Universidade Federal de Goiás. O objetivo do estudo foi buscar compreender quais os possíveis fatores que levaram a instituição, denominada na época, Escola Industrial de Cuiabá, a iniciar estudos de viabilidade para a implantação do Curso Técnico em Estradas no início da década de 1960. A abordagem da pesquisa foi histórica, contando com um corpus documental composto da legislaçáo, de documentos do acervo atual do Instituto Federal de Mato Grosso e em diversos acervos do estado de Mato Grosso. As análises produzidas permitem afirmar que a implantação do Curso Técnico em Estradas foi idealizada como forma de inserir mão de obra técnica de qualidade no processo de expansão da malha viária do estado implementado pelo Programa Estratégico de Desenvolvimento nas décadas de 1960 e 1970.

Palavras-chave: Curso Técnico de Ponte e Estradas. Curso Técnico em Estradas. Escola Técnica Federal de Mato Grosso.

1 Mestre em Educação pela Universidade Federal de Goiás (UFG), professor do Instituto Federal de Educação, Ciência e Tecnologia de Mato Grosso. E-mail: pedrojose.barros@gmail.com.br

2 Doutora em Educação, professora do Programa de Pós-Graduação em Educação da Faculdade de Educação da Universidade Federal de Goiás. E-mail: miriamfabia@gmail.com 


\section{Introdução}

Este artigo é um recorte da dissertação de mestrado intitulada "O curso Técnico em Estradas: das origens à implementação na Escola Técnica Federal de Mato Grosso", desenvolvida no âmbito do Programa de Mestrado Interinstitucional em Educação celebrado entre a Faculdade de Educação da Universidade Federal de Goiás (UFG) e o Instituto Federal de Educação, Ciência e Tecnologia de Mato Grosso (IFMT). A pesquisa está vinculada à linha de "Estado, Políticas e História da Educação" e teve o objetivo de investigar os motivos que levaram a Escola Industrial de Cuiabá (EIC), instituição vinculada à Rede Federal de Educação Profissional, à criação do Curso Técnico em Estradas no início da década de 1960, época em que o país estava em momento histórico, sob o domínio autoritário do regime militar.

Para compor esta pesquisa, foi realizada uma busca minuciosa em diversos acervos de fontes no estado de Mato Grosso, a partir da qual constatou-se a falta de informaçóes escritas sobre o curso, bem como que sua história tem sido apenas contada verbalmente por ex-alunos e servidores que presenciaram sua existência. Tal situação motivou a pesquisa e a tentativa de elucidar um pouco do processo de implantação do Curso de Estradas.

Assim, o ineditismo deste estudo e as possíveis contribuiçôes que este trabalho pode trazer para a história da educação de Mato Grosso impulsionaram este trabalho.

O IFMT - Campus Cuiabá, situado secularmente no mesmo espaço da Escola de Aprendizes Artífices de Mato Grosso (EAAMT), criada em 1909, remodelada para atender as reformas, passando a ser denominada de Liceu Industrial de Cuiabá (1941-1942). Logo depois passou a ser denominada por, respectivamente, Escola Industrial de Cuiabá (1942-1965), Escola Industrial Federal de Mato Grosso (1965-2002), Centro Federal de Educaçáo Tecnológica de Mato Grosso - CEFET MT (2002-2009) e, desde entáo, Instituto Federal de Educação, Ciência e Tecnologia de Mato Grosso (FIGUEIREDO, 2017).

Nesse sentido, se faz necessário considerar que essa instituiçáo completará 109 anos, em 23 de setembro de 2018, e assim como as outras instituiçóes criadas na época, em meio às dificuldades encontradas, promoveu significativas transformaçóes nas práticas sociais, educacionais e no trabalho, no estado de Mato Grosso. 
$\mathrm{Na}$ tarefa de compreender esse contexto, recorreu-se a pesquisas que se dedicaram a analisar a história da educação profissional no Brasil com autores como Cunha (2000), Fonseca (1961), Franco (1984), Machado (1982), Manfredi (2002), Prescivalle (1982), entre outros. Para tratar, especificadamente, sobre a educação profissional em Mato Grosso, elegeram-se os estudos de Volpato (1993), Crudo (1999), Silva (2001), Kunze (2006), Francisco (1998), Oliveira (2009), dentre outros.

Assim, ao buscar referências sobre as instituições de educação profissional no recorte da pesquisa, notou-se um relevante desafio para encontrar documentos e informaçóes específicas referentes ao Curso Técnico em Estradas, mesmo no período em que a ETFMT era denominada Escola Industrial de Cuiabá nas décadas de 1940 e 1950.

Contudo, o material encontrado no acervo do IFMT, em forma de documentos, tais como Atas do Conselho de Representantes da Instituição, Resoluçóes, Pareceres, entre outros, tratava-se de informaçóes isoladas e sem conexão aparente com o foco principal da pesquisa, além de não trazer informações sobre os motivos da criação de um curso técnico na Escola Técnica Federal de Mato Grosso. O corpus documental também foi composto por atas, resoluçóes, recortes de jornal, imagens, dentre outros, que estavam distribuídos em inúmeros acervos de Mato Grosso ${ }^{3}$.

Mas, considerando que o papel do historiador é reunir os fragmentos da história e escrever a narrativa sobre o objeto em estudo, buscou-se responder à seguinte questão: que trajetória histórica levou a ETFMT a ofertar o Curso Técnico em Estradas em meados da década de 1960? A questão norteadora levou a uma busca ampliada sobre as fontes que permitiram identificar algumas hipóteses relacionadas às necessidades expansionistas, tanto do governo federal, como do governo estadual desde o início do século XX, culminando com a necessidade de introduzir mão de obra qualificada para dar suporte aos planos desenvolvimentistas que impulsionavam o estado na abertura de estradas e na colonização da região norte do estado de Mato Grosso, iniciadas na década de 1950.

3 Os acervos pesquisados são de algumas instituiçóes importantes, como Biblioteca e Arquivo Permanente do IFMT/Campus Cuiabá-Octayde Jorge da Silva, Arquivo Público de Mato Grosso (APMT); Arquivo e Biblioteca da Casa Barão de Melgaço (ACBM-MT), Arquivo da Receita Federal em Mato Grosso (ARFMT); Museu da Imagem e do Som de Cuiabá (MISC); $9^{\circ}$ Batalhão de Engenharia de Construção ( $9^{\circ}$ B.E.CNST), Serviço Nacional de Aprendizagem Comercial de Mato Grosso (SENAC-MT), e Center for Research Libraries (CLR). 
Nesse sentido, buscou-se investigar os primeiros trâmites do processo de instalação e funcionamento do Curso Técnico em Estradas, iniciado na extinta Escola Industrial de Cuiabá, como foi instituído, considerando os diversos aspectos envolvidos, como a política educacional nacional, desenvolvimento regional, interesses internos e externos do cotidiano escolar que vieram dar suporte à criação do curso.

O presente artigo foi organizado em duas partes: na primeira se discute como o Curso Técnico em Estradas nasceu imbricado com a expansão do território brasileiro e a necessidade de construção de estradas que requeriam a formação de mão de obra. No segundo momento se discutem os movimentos de criação do Curso Técnico em Estradas na Escola Industrial de Cuiabá/ Escola Industrial Federal de Mato Grosso.

\section{Mato Grosso e a expansão do território brasileiro: a construção de estradas e a necessidade de formação de técnicos}

A percepção do tamanho do território brasileiro, o isolamento econômico e a manutenção da defesa da integridade do território, preservando, assim, a unidade nacional, estiveram presentes na preocupação dos governantes desde o período colonial até o republicano. Dessa preocupação, decorrente de numerosas tentativas de invasão das colônias por outros países europeus, surgiu a necessidade de interligar e povoar as colônias, como estratégia de preservação das fronteiras.

No início do século XX, movimentos de expansão territorial e de busca de povoamento do interior do país influenciaram as políticas de expansão regional no estado de Mato Grosso, principalmente a construção de estradas, a fim de incentivar a colonização da região norte do estado.

Nessa direção, outras evidências encontradas reforçam a hipótese inicial de que a criação do Curso de Estradas se insere nesse movimento expansionista crescente: em 1937 o governo federal, ao publicar o Plano Nacional de Estradas e Rodagens (PNER), previu a ligação do sul do país à regiáo amazônica, passando pelo Planalto Central. Esse planejamento pode ter influenciado o governo federal a desenvolver políticas voltadas ao ensino industrial, o que levou a fortalecer e incentivar a produçáo de mão de obra qualificada através das escolas técnicas existentes ao longo desse eixo rodoviário. 
Essa questão também se fortalece pelo fato de que, pela primeira vez, o governo da União, através do Decreto n. 8.673/1942, aprovou o "Regulamento do Quadro de Cursos do Ensino Industrial”, inserindo no seu escopo o Curso de Pontes e Estradas (BRASIL, 1942). Assinala-se ainda que, no estado de Mato Grosso, o Curso Técnico em Estradas passa a ter evidência em 1965, época em que não havia disponibilidade de mão de obra especializada para dar suporte às exigências do setor de engenharia que atuaria nas frentes de serviço para abertura de estradas, construção de pontes, e obras consideradas importantes para possibilitar a colonização e desenvolvimento do estado de Mato Grosso.

Para subsidiar a fundamentação deste artigo, nos reportamos a Moreno (2007), quando este tece algumas análises sobre a ocupação e desenvolvimento no interior de Mato Grosso. Para Moreno (2007), as análises sobre documentos e informaçóes sobre as açóes fundiárias desenvolvidas pelo Estado a partir de 1892, por ocasião em que este passa a ter domínio sobre as terras devolutas dentro do seu território, foram "entendidas" como políticas de regularização fundiárias. Contudo, essa regularização era feita sem maiores critérios, concedendo ou não o direito de preferência à titulação das terras. Assim, um dos objetivos principais seria a distribuição de terras no território mato-grossense:

[...] - colonização oficial e particular, segundo uma política maior, empreendida pelo Governo Federal, para a ocupação dos "espaços vazios" e sua integração à economia nacional, principalmente na sua fase recente de acumulação capitalista. (MORENO, 2007, p. 26).

A política de integração foi utilizada por iniciativas de diversas legislaturas no governo federal, como também dos estados, em particular em Mato Grosso. Essas práticas foram utilizadas para dar consistência à política de integração, sendo justificada em açóes governamentais para o desenvolvimento e ocupação dos "espaços vazios" por meio de construção de estradas.

Na década de 1950, a criação da Superintendência do Plano de Valorização Econômica da Amazônia ${ }^{4}$ foi um importante instrumento para desencadear a política de integração, a qual era destinada a incrementar o desenvolvimento da produção extrativa e agrícola, pecuária mineral, industrial e as políticas

4 Criada pela Lei n. 1.806, de 6 de janeiro de 1953. 
das relaçóes de troca com a finalidade de melhorar os padróes sociais de vida e do bem-estar econômico das populaçóes das diversas regióes Centro-Oeste e Norte do país.

Um dos objetivos principais dessa lei era realizar um plano de viação da Amazônia, que compreenderia todo o sistema de transportes e comunicaçóes, considerando as peculiaridades do complexo hidrográfico, sua extensão e importância na economia regional, assim como as bases econômicas e técnicas de sua gradual execução (BRASIL, 1953).

Na região central do país, a existência de amplas áreas, ditas "despovoadas", passou a ser objeto de discussóes no Parlamento com a intenção de mudança da capital federal para o Planalto Central, que acaba acontecendo no final da década de 1950 e início da década seguinte.

Nos governos de Vargas e Kubitschek desencadeiam e consagram a ideia de "isolamento nacional" como política pública para a integração nacional, traduzida na ideologia nacionalista da Marcha para o Oeste ${ }^{5}$, depois encampada pela Fundação Brasil Central ${ }^{6}$ na Expedição Roncador-Xingu, alavancando grandes obras rodoviárias e a própria construção de Brasília. Esta era a estratégia: promover a integração do território nacional a partir de rodovias que de lá partiriam, e alcançariam os extremos do país, conforme demonstra Huertas (2009, p. 75):

Era preciso dar um salto para o futuro, "desenvolver 50 anos em 5", com um programa de investimentos distribuídos entre os setores de energia, transporte, alimentação, indústria de base e educação. Mas se tornava essencial atrair mão de obra, capitais e empreendimentos para o coração do Brasil, e a nova capital, a cerca

5 Somente a partir da década de 1940 a política estadual de colonização voltou a ser implementada com a 'Marcha para o Oeste', política de ocupação dos "espaços vazios" do Oeste e da Amazônia posta em prática pelo governo ditatorial de Vargas (1930/1945), visando à expansão da fronteira agrícola nacional a partir da criação de 'colônias agrícolas nacionais'. Com essa política, pretendia-se diversificar a produção necessária ao abastecimento alimentar dos centros urbanos e ao fornecimento de matérias-primas para o desenvolvimento industrial em curso no país desde a ascensão de Vargas ao poder, em 1930 (MORENO, 2007, p. 54).

6 A Fundação Brasil Central foi uma agência criada por ocasiāo da Expedição Roncador-Xingu, empreendimento iniciado em 1943 por iniciativa do então ministro da Coordenaçáo de Mobilização Econômica, João Alberto Lins de Barros. Tinha como missão: "o desbravamento e a colonização das regióes do Brasil Central e Ocidental, notadamente as dos altos rios Araguaia e Xingu”. A FBC funcionou com este nome até 1967, quando foi extinta e suas atividades foram incorporadas à Sudeco (Superintendência de Desenvolvimento do Centro-Oeste) - (MAIA, 2012.) 
de mil quilômetros da faixa litorânea, significava o rompimento definitivo com a velha concepção da vocação agrícola do Brasil. Assim, o governo propóe uma guinada no curso do desenvolvimento nacional, levando-o para o interior, e incentiva a industrialização com o consequente alargamento do mercado interno.

Ao contribuir e dar sustentação a essa política de integração nacional, outras rodovias ganharam destaque nesse período, como a BR-29 (atual BR364), ligando Brasília a Rio Branco, no Acre, passando por Cuiabá, em Mato Grosso, e Porto Velho, em Rondônia; e a BR-14 (atual BR-153), ligando Brasília a Belém, no Pará. A figura 1 ilustra a configuração dessa malha viária.

Figura 1 - Mapa da configuração das BRs 14 e 29, no governo de Juscelino Kubitschek

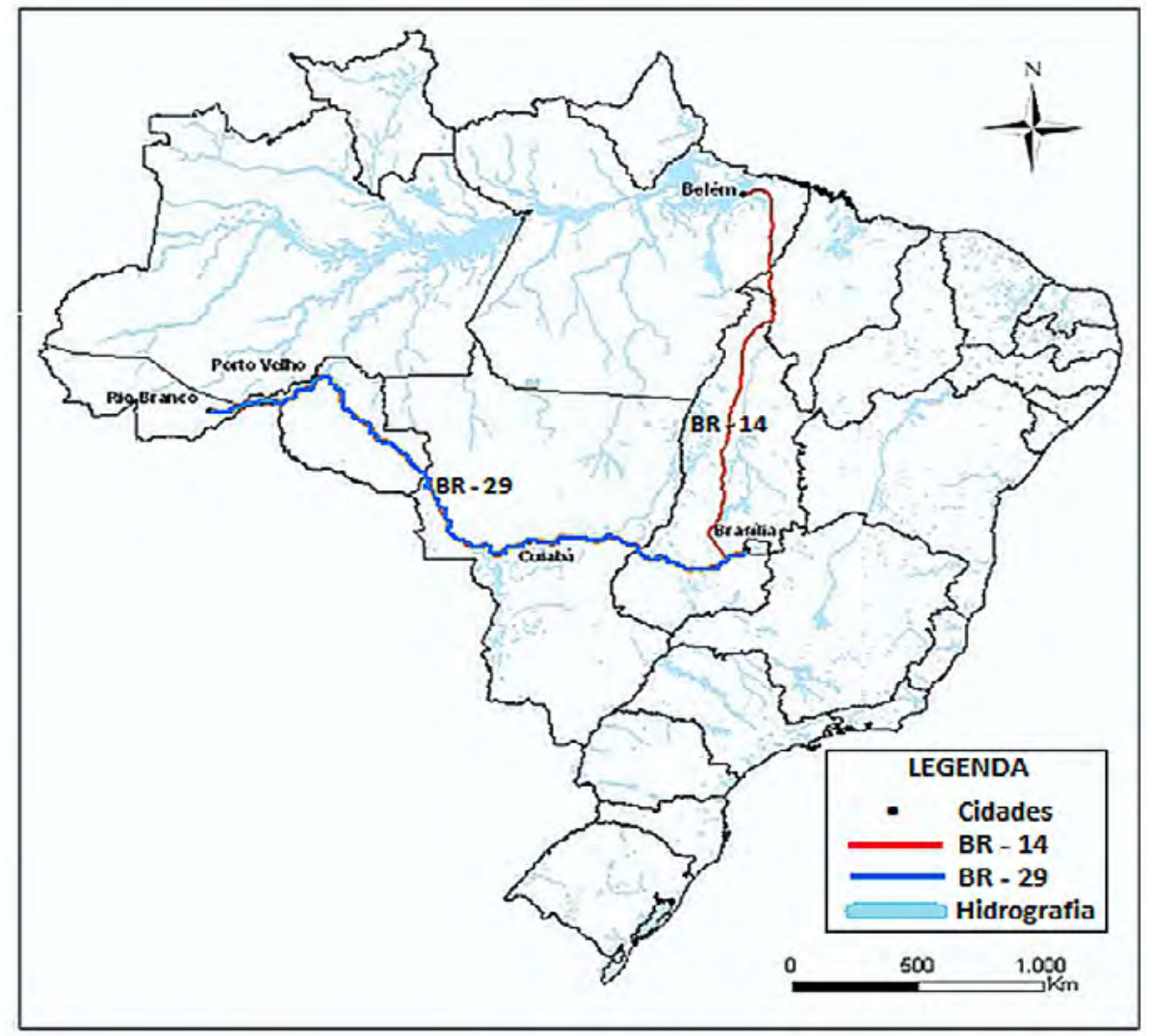

Fonte: Margarit (2012, p. 18). 
Essa política de integração nacional, cuja origem remonta ao período do governo Vargas, visava radicalizar a modernização do país, através da expansão das fronteiras com a abertura de estradas pelo interior dos estados tendo em vista tanto a ocupaçáo dos espaços, quanto o desenvolvimento urbano industrial, através do fortalecimento da economia e implementação de indústrias de base.

Assim, o período compreendido entre os anos de 1956 e 1960, no contexto do desenvolvimento industrial, caracterizou-se por grandes transformaçôes no sistema econômico brasileiro. $\mathrm{O}$ processo de industrialização não se dava, apenas, para substituir as importaçóes, mas também alcançava um expressivo nível de diferenciaçáo, conseguida a partir de um processo de desenvolvimento interno, favorecendo as indústrias básicas, promovendo grande incentivo aos setores públicos e principalmente aos privados.

Nesse sentido, como consequência a implementação da política econômica do governo Kubitschek, definida no Programa de Metas, tinha como foco atingir um conjunto de objetivos voltados para a área de energia, transportes, alimentação, indústria de base, educação, o que culminou com a construção de Brasília.

Nesse processo, a política econômica posta em prática, segundo Fausto (2008, p. 427), tratava de combinar o Estado, a empresa privada nacional e o capital estrangeiro para promover o desenvolvimento, com ênfase na industrializaçáo. Assim, o governo propóe mudanças a serem assumidas no campo da educaçáo profissional, com incentivos para o crescimento da oferta de cursos técnicos na década de 1960.

\section{Curso Técnico em Estradas na Escola Técnica Federal de Mato Grosso: movimentos iniciais}

Mesmo com a autonomia adquirida com a Lei n ${ }^{\circ} 3.552$, de 1959, a Escola Industrial de Cuiabá continuou oferecendo apenas a formaçáo industrial básica já ofertada anteriormente. Entretanto, o antigo anseio da comunidade escolar de ver a escola ser transformada em Escola Técnica ganhou vulto por ocasião da instalação do Conselho de Representantes ${ }^{7}$, em 26 de maio de 1961.

7 Conselho de Representantes (CR): órgão responsável pela administração da escola e constituído por representantes da indústria e de outros setores da sociedade civil e da própria instituição. Apesar da autonomia adquirida a partir da Lei 3.552/1959. 
Neste ato, a Diretoria da EIC passou a ser um órgáo coordenador executivo das atividades da Escola subordinado ao Conselho de Representantes, e uma das suas atribuiçóes era aprovar a organização dos cursos, cuja discussão e aprovação prévia caberiam ao Conselho de Professores. Assim, a Escola Industrial de Cuiabá, além de instalar o Conselho de Representantes, tinha que constituir um Conselho de Professores, como previsto na Lei 3.552/59 (BRASIL, 1959).

Outra exigência prevista na legislação, como importante requisito para a oficialização da autonomia e aquisição da personalidade jurídica própria da instituição, era o regimento da Escola Industrial de Cuiabá, cuja aprovação se deu pela Resolução n ${ }^{\circ}$ 5, de 11 de setembro de 1961 (ESCOLA INDUSTRIAL DE CUIABÁ, 1961-1966, f. 19-22).

Esse período de transformaçóes na gestão da instituição, que coincidiu com o término das obras da EIC, se estendeu até o final da década de 1960 e com o crescimento urbano de Cuiabá. Segundo Freire (1997), esse crescimento imprimiu novos traçados urbanísticos que romperam com a fisionomia barroca tradicional da cidade e produziu nova dinâmica ao traçado urbano.

Além disso, devido ao processo de ocupação do território do Centro-Oeste e da Amazônia, o estado obteve recursos federais de investimentos utilizados na construção de novos edifícios, redirecionando o crescimento da cidade, de maneira a agrupar novas áreas de mais fácil apropriação. Assim, a Escola Industrial de Cuiabá recebeu investimentos para a conclusão das edificaçóes na década de 1950 e, na década seguinte, já se apresentava com traços modernos na sua estrutura física recém-construída.

O Conselho de Representantes e a Diretoria da EIC passaram a priorizar seus esforços para atender o quanto antes às exigências necessárias à reestruturação da Escola Industrial de Cuiabá para sua transformação em escola técnica, dentre essas exigências, a revisão do Regimento Interno.

Essa mudança apresentou duas alteraçôes significantes, que necessitavam de ser regulamentadas o quanto antes.

A primeira foi a mudança da denominação da instituição para Escola Industrial Federal de Mato Grosso em atendimento à Lei no 4.759, de 20 de agosto de 1965 e sua normativa complementar, Portaria do Ministério da Educação e Cultura 
n. 239 , de 3 de setembro de $1965^{\circ}$. A segunda se referiu à inserção de cláusulas autorizadoras e regulamentadoras da criação e implantação de cursos técnicos, que era uma das condiçóes exigidas à instituição para se caracterizar como uma escola técnica (ESCOLA INDUSTRIAL DE CUIABÁ, 1961-1966, f. 160-306).

Kunze (2011) afirma que a diretoria recebeu autorização do Conselho (Resolução n. 41, de 26 de maio de 1965) para programar os estudos necessários ao oferecimento dos Cursos Técnicos de Estradas e de Eletrotécnica, que ficaram a cargo do engenheiro eletricista professor Frederico Carlos Soares Campos. A escolha desses dois cursos correspondia às demandas de técnicos dessas duas áreas, pois, em Mato Grosso, a abertura de novas estradas para interligação regional e escoamento da produção agrícola se acelerava, além de a produção de energia elétrica começar a receber investimentos para a resolução do secular problema de insuficiência desse recurso, que prejudicava a inserção das indústrias na região (ESCOLA INDUSTRIAL DE CUIABÁ, 1961-1966, f. 229).

No que diz respeito aos cursos de formação técnica, Kunze (2011, p. 98) refere-se à criação dos cursos (Estradas e Eletrotécnica em 1965) como uma sintonia que deveria existir entre a instituição e o desenvolvimento rodoviário e energético, estimulado pelo governo do Estado:

A escolha desses dois cursos correspondia às demandas de técnicos dessas duas áreas, pois em Mato Grosso a abertura de novas estradas para interligação regional e escoamento da produção agrícola se acelerava, e a produção de energia elétrica começava a receber investimentos para a resolução do secular problema de insuficiência desse recurso, que inclusive prejudicava a inserção das indústrias.

Depois de alguns meses, o relatório do professor Frederico Campos foi apresentado à Direção da Escola no dia 18 de setembro de 1965. O minucioso

8 Essa legislação qualificava as Universidades e Escolas Técnicas da União, sediadas nas capitais dos Estados, como instituições federais que deveriam ter a denominação do respectivo Estado (BRASIL, 1965). 
documento apresentou estudos que tiveram como referência os programas adotados pela Escola Técnica Nacional do Rio de Janeiro e descreve as propostas que deveriam ser avaliadas pela instituição para que fosse possível o início das atividades no exercício de 1966 para os dois cursos: Estradas e Eletrotécnica.

Logo no início do mês de fevereiro de 1966, o diretor da Escola Industrial Federal de Mato Grosso (EIFMT) apresentou ao Conselho de Representantes relatos de sua visita ao Ministério da Educação e Cultura, no qual tratou de problemas administrativos da escola e principalmente em relação à implantação de cursos técnicos.

Na reunião, explanou que, devido ao Decreto9 no 57.630, de 14/01/1966, da Presidência da República, a escola estaria impossibilitada de admitir novas contrataçóes de professores, por causa do contingenciamento de despesas da União. Diante disso, em relação aos dois cursos previstos, Eletrotécnica e Estradas, ficou decidido que apenas o Curso Técnico de Eletrotécnica teria início contando com o corpo docente da instituição.

Assim, o Curso de Estradas só iniciou suas atividades letivas no mês de abril de 1967, com uma turma composta por 29 alunos. Os professores de cultura geral continuaram sendo os mesmos existentes na instituição. Já os professores de cultura técnica, devido às particularidades técnicas de algumas disciplinas inerentes à formação profissional, tiveram que ser contratados como prestadores de serviço por tempo determinado. É possível observar também nesse trabalho que não existia nenhum profissional com conhecimento técnico de nível médio ou superior no estado para atuar nesse novo segmento profissional.

O técnico em Estradas situava-se no estado, como único profissional de nível médio com os requisitos profissionais compatíveis para atuar no campo de infraestrutura de construção, conservação de estradas, pontes e obras de arte. Os conhecimentos teórico e prático incorporados a sua profissão foram de extrema importância para sua atuação no mercado de trabalho.

Inicialmente, por ser um curso novo, repleto de informaçóes técnicas e teóricas que não valeriam de nada se não fossem atreladas às práticas de campo. Segundo relatos de professores e ex-alunos do curso, os professores

9 Decreto $n^{\circ}$ 57.630, de 14 de janeiro de 1966. Art. 11. Ficam sem efeito, a partir da data da publicação deste Decreto, as nomeações e admissões feitas depois de 31 de dezembro de 1965, para quaisquer órgãos da administração centralizada ou autárquica, sem prévia e expressa autorização do Presidente da República. 
foram profissionais que se engajaram no objetivo primordial do curso: preparar profissionais altamente habilitados para operar nas adversidades que esta modalidade de curso tinha como desafio.

Os alunos, de maneira geral, em especial os integrantes da primeira turma, foram os pioneiros e acreditaram na instituição e no empenho dos professores na formação técnica com alto nível de conhecimento para atuar profissionalmente no mesmo nível de conhecimento em relação a profissionais com formação de nível superior.

\section{Algumas reflexões finais}

Observando a trajetória da educação profissional no nosso país, assim como as diversas fases da sua constituição, podemos compreender as inúmeras motivaçôes que nortearam a sua história. É possível perceber que a sua constituição foi lenta e gradual, construindo sua credibilidade, de modo a contribuir para criação de uma rede federal de educação profissional que foi se tornando instituição sólida, como as que temos nos dias de hoje.

Não seria possível compreender a evolução dos Institutos Federais se não nos reportarmos às primeiras instituiçóes de ofícios no período da Colônia, do Império e do início da era republicana, por ocasião da criação das EAAs. Nesse percurso, no qual as dezenove instituiçóes foram protagonistas imprescindíveis na construção de uma história, embora repleta de avanços e retrocessos, serviram para que cada escola em cada estado superasse seus desafios e se transformassem em instituiçôes cada vez melhores.

Em Mato Grosso, não foi diferente, tampouco sem dificuldades. Se considerarmos que a EAAMT é geograficamente prejudicada em função das enormes distâncias em relação aos grandes centros, certamente teve grandes dificuldades na sua estruturação. Nesta pesquisa, é possível constatar que somente nas décadas de 1940 e 1950 a instituição começou a ter um significativo impulso na sua reestruturação física e educacional.

Nesse período, com a inserção da regiáo Centro-Oeste no plano de expansão político-econômico, voltado à produção agrícola e industrial, agregado ao movimento de integraçáo do país através da Marcha para o Oeste, acontece um impulso no desenvolvimento do estado de Mato Grosso, de modo a se estender a várias frentes de desenvolvimento, envolvendo, entre outras questôes, como de ordem urbano-social. Assim, a instituição também 
foi beneficiada quando recebeu considerável incentivo financeiro para dar suporte ao seu crescimento, principalmente na sua estrutura física.

Esse movimento de integração despontou como um dos fatores que contribuíram para a implantação de cursos técnicos, já em discussão no início da década de 1960. A integração nacional proposta por Getúlio Vargas e posteriormente por Juscelino Kubitschek, além de indicar a colonização de terras "desabitadas" expandindo o território mato-grossense, almejava integrar as fronteiras agrícolas. Para isso, necessitava de um novo modelo de produção que desse suporte ao crescimento do interior do estado. Contudo, duas grandes barreiras sempre foram empecilho: a necessidade de aumentar a malha viária e o sistema energético do estado.

$\mathrm{O}$ aumento da malha viária no estado proporcionou um grande impulso na economia de Mato Grosso, principalmente após o início do governo militar, que disponibilizou recursos para a implantação de infraestrutura de modo a promover o desenvolvimento do interior do estado às margens das rodovias ali construídas.

Inegável também o papel do governo federal no fortalecimento do segmento da educação profissional, aumentando a oferta de cursos técnicos nas diversas escolas técnicas do Brasil. Desta forma, na Escola Técnica Federal de Mato Grosso, a opção pelo Curso Técnico em Estradas se deve em grande parte pela necessidade do aumento de mão de obra especializada para o desenvolvimento do setor de infraestrutura na construção e recuperação de uma malha viária condizente com o desenvolvimento do estado.

Assim o Curso Técnico em Estradas passou a ser considerado como importante produtor de mão de obra qualificada para atuar nas várias frentes de trabalho ligadas à construção de estradas no estado de Mato Grosso.

É possível perceber ao longo deste estudo que a instituição esteve sintonizada com o aparelho estatal na contrapartida de oferta de cursos que representassem os interesses da Uniáo, a fim de alavancar a economia do País. Além disso, sabemos também que os interesses não só beneficiaram a populaçáo como um todo, mas também os grandes grupos econômicos que comandavam os destinos da economia, direcionando os rumos da tecnologia, da ciência e da formação de recursos humanos que, historicamente, sempre atuaram no processo de colonização do estado.

Enfim, o Curso Técnico em Estradas representou uma marca indelével na história da Escola Técnica Federal de Mato Grosso. 


\section{REFERÊNCIAS}

BRASIL. Ministério da Educação e cultura. Decreto 58.749, de 28.06.66. Exclui da proibição constante do artigo $5^{\circ}$ do Decreto no 57.630 , de 14 de janeiro de 1966 , dispóe sobre a nomeação interina para o cargo vago que especifica. Diário Oficial da Uniáo, em 14/07/1966.

. Portaria n. 239, de 03/09/65. Dispóe sobre a denominação e qualificação das Universidades e Escolas Técnicas Federais. Coord. de Arquivo, Img. 0769 e Img. 0770, Caixa 02, Código 020.1.

CÂMARA FILHO, Jeremias Pinheiro da. Relatório da visita feita à . 1963. In: ESCOLA INDUSTRIAL DE CUIABÁ. Livro de Atas do Conselho de Representantes da EIC N. I, Cuiabá, 1961-1966, f. 97-100.

COSTA, Eliete Hugueney de Figueiredo; PEREIRA, Maria Auxiliadora Silva; KUNZE, Nádia Cuiabano. Trabalhos Acadêmicos: passo a passo. 2. ed., rev., ampl., atual. Cuiabá: EdUFMT, 2015.

ESCOLA INDUSTRIAL DE CUIABÁ. Ata de 01/10/1963: apresenta o relatório do supervisor das EICs. Livro de Atas do Conselho de Representantes da EIC N. I, Cuiabá, 1961-1966, f. 97-100.

ESCOLA INDUSTRIAL DE CUIABÁ. Carta de 15.10.63, do Supervisor Jeremias Pinheiro da Câmara a servidores da EIC. Coord. de Arquivo, Img. 0690 e Img. 0692, Caixa 20, Código 011.

FAUSTO, Boris. História Concisa do Brasil. 2. ed. São Paulo: EdUSP, 2008.

FIGUEIREDO, Túlio M. R. V. O Brasil moderno e a educaçáo para o trabalho em Cuiabá: a Escola de Aprendizes Artífices de Mato Grosso (1909-1942). 2017. Dissertação (Mestrado em Educação)- Universidade Federal de Goiás, Goiânia, 2017.

FREIRE, Júlio De Lamônica. Por Uma Poética Popular da Arquitetura. Cuiabá: EDUFMT, 1997.

KUNZE, Nádia Cuiabano. A Escola de Aprendizes Artífices de Mato Grosso 1909/1941. São Paulo: Câmara Brasileira do Livro, 2006.

, Nádia Cuiabano. As primeiras Escolas Públicas de Ensino Profissional em Mato Grosso. In: 2a JORNADA DA PRODUÇÃO CIENTÍFICA DA EDUCAÇÃO PROFISSIONAL E TECNOLÓGICA DA REGIÃO CENTRO OESTE, 2008.

. Nádia Cuiabano. Escola Industrial de Cuiabá: gênese e organização (19421968). 2011. Tese (Doutorado em Educação)-Faculdade de Educação da Universidade de São Paulo, São Paulo, 2011.

Nádia Cuiabano. O desenvolvimento da rede federal de escolas industriais e técnicas a partir de 1942. Texto apresentado para o Curso de Gestão Pedagógica do IFMT, 2012. 
MARGARIT, Eduardo. In: Tramas políticas e impactos socioambientais na Amazônia: a dinâmica do processo de pavimentação da BR-163, 2012.

MORENO, Gislaene. Terra e poder em Mato Grosso. Política e mecanismos de burla, 1892-1992. Cuiabá: Entrelinhas, Ed UFMT, 2007.

MOURA, Elma Coelho Martins. O ensino da Matemática na Escola Industrial de Cuiabá-MT no período de 1942 a 1968. 2012. Dissertaçáo (Mestrado)- Instituto de Geociências e Ciências Exatas do Campus de Rio Claro, Universidade Estadual Paulista Júlio de Mesquita Filho, Rio Claro, São Paulo, 2012.

SANTOS, Jailson Alves dos. A trajetória da educação profissional. In: LOPES, et al. (Org.). 500 anos de educaçáo no Brasil. 2. ed. Belo Horizonte: Autêntica, 2000. p. 205-224.

SEMAN, C. Breve Histórico Sobre a Evoluçáo do Planejamento Nacional de Transportes. DNIT - Departamento Nacional de Infraestrutura de Transportes. Belo Horizonte, 2010. 